\title{
INVESTMENT IN CONSTRUCTION AND ECONOMIC GROWTH: A LONG-TERM PERSPECTIVE
}

\section{J. LOPES}

Department of Construction and Planning, School of Technology and Management, Polytechnic Institute of Bragança

Apartado 1134, 5301-857 Bragança, Portugal

E-mail: lopes@ipb.pt

\section{Introduction}

The role of construction in economic growth and development has been addressed by various writers and international bodies, many of whom have focused in developing countries (Turin, 1973; World Bank, 1984; Wells, 1986; Bon, 1990). Bon (1992), analysed the changing role of the construction sector at various stages of economic development and presented a development pattern for the industry based on the stage of development of a country's economy. The main aspects of the proposition were that, in the early stages of the economic development, the share of construction in gross domestic product (GDP) increases but ultimately decreases in industrially advanced countries. Turin and Wells, using cross-country comparisons, both found an association between construction investment and economic growth. That finding was consistent with the classical approach in growth theory in which physical capital formation is the main engine of economic growth and development. In the aftermath of the !979-980 oil-shock and the international financial crisis that followed in 1981, most of Sub- Saharan African countries experienced until the mid-1990s a decreasing growth in per capita national income, despite heavy investment in construction and other physical capital over the preceding decade.

Another approach to the theory of growth (Romer, 1990; Barro, 1991, Olsen, 1995) was emerging. Following this endogenous growth theory, endogenous policy changes (e.g. macroeconomic stability, investment in human capital, research and innovation) play an increasing role in the development process. De Long and Summers (1991), using data from the United Nations Comparison Project drawn 
from 61 countries representing all stages of economic development, found that machinery and equipment investment have a strong association with economic growth. Further, they put forward evidence that structures investment is only weakly associated with growth. World Bank (1994) posited that rather that the quantity of infrastructures the main concern in developing countries should be the improvement of the quality of infrastructures. Thus, it is reasonable to argue that this would be achieved through an adequate maintenance of existing infrastructure stocks and by prioritising investments that modernise production and enhance international competitiveness. In the Structural Adjustment Programme for Africa, The World Bank and its affiliates seemed also to follow the view that investment should accompany economic growth.

The remaining of this chapter presents the statistical sources and the indicators of the economic activity chosen for the analysis. Secondly it provides a historical review of the process of economic growth. Next it presents and analyses the pattern of development of construction investment in the world economy as well as in the world regional groups. A concluding remark finalizes the analysis.

\section{2-Statistical sources and methodology of data collection and presentation}

The main statistical sources used in this analysis are the most recent edition of the Yearbook of National Account Statistics: Main Aggregates and Detailed Tables from the United Nations and World Development Report from the World Bank (1992 and 2008 eds). The internet site of the UN statistical office presents data on gross domestic product (GDP) and its components both in the expenditure and production approaches. This publication presents various sets of economic series detailing the evolution of GDP and its components in different statistical formats over the long period 1970-2006, both in the world, world regions and countries: at current prices in national currencies; constant 1990 prices in national currencies; current prices in US dollars; constant 1990 prices in US dollars: The indicators of economic activity 
analysed are: GDP, construction value added (CVA) and gross fixed capital formation. Unfortunately, data on gross fixed capital formation in construction (GFCFC) are not provided in the UN publication. The latter indicator is provided for the period 1960-2006 in two publications of the Organisation for the Economic Cooperation and Development (OECD; 1998; OECD, 2008): Thus, CVA is used as a proxy for analysing the evolution pattern of construction investment across the world and world regions. Indeed, as pointed out in Lopes (1997), since World War II, when international bodies, particularly the United Nations, started publishing data on the construction sector, there has been a remarkable uniformity across countries on the value of $50 \%$ as the average contribution of capital formation in construction to a country's domestic investment. As construction value added is roughly a half of the former, it appears reasonable that CVA can be used as a surrogate measure of construction investment. In order to facilitate international comparison as well as for aggregation purposes, constant 1990 prices in US dollars are used: With respect to the investigation of the relationship between the construction sector and economic development according to a country's (group of countries) stage of economic development, gross national product (GNP) per capita for the bench mark years 1990 and 2006 has been chosen. These are provided by World Bank (1992; 1998). The World Development Report 1992 presents the following definitions. Income Group: The economies are divided according to 1990 GNP per capita. The groups are: low income economies (LIEs), US\$ 610 or less; lower- middle- income (LMIEs), US\$ 611-2, 465; upper-middle-income (UMIEs), US\$ 2,412-7,619; and high income economies (HIEs), US\$ 7,620 or more. Subgroup: LIEs are further divided by size, and HIE by membership of OECD. Region: Economies are divided in five major regions and eight additional subregions.

\section{3-A historical review of the processes of economic growth}

This section presents a review of the historical experience of the economic growth of nations, especially of today's advanced industrial countries, in order to have a whole 
picture of the nature of the economic factors that are conductive to the long-term economic growth and development. Data presented here cover generally the period between 1870 and 1984, and in some cases go back as far as 1750. Growth accountancy owes much to the work of Simon Kuznets and who received the Nobel Prize in economics in 1971 for his pioneering work in the measurement and analyses of the historical process of economic growth in developed countries (Todaro, 1992). Most modern studies on growth accountancy (Denison, 1985; Hickman and Coen, 1987; Maddison, 1987; Chenery et al, 1988, to name but a few) and the modern methodology of national accounts are based on the conceptual framework prepared by Kuznets. Another great student of growth accounting is Angus Maddison. In his monumental work (The World Economy: A Millennium Perspective), Maddison (2008) provides a fascinating accounting exercise on, in Lucas'(1992 words, the mechanics of the economic growth of nations from 0 A.D. until the present time.

\section{3-1 Trends in the growth of national product}

The national income or total net product of a country is the sum of all goods and services during a given period, usually one year, adjusted for duplications, and net for any commodity consumed in the process of production.

Estimates made by Kuznets (1968) on a sample of countries representing $80 \%$ of the world population in 1950 found that over $30 \%$ had per capita income of less than $\$ 50$ and almost one quarter, between $\$ 50$ and \$100 (U.S. dollars, 1949 constant prices). On the top of the income per capita pyramid were the U.S., UK, the Scandinavian countries, The Netherlands, France, Canada, Australia and New Zealand which had a per capita income of $\$ 600$ or more. Taking in account that the countries in which data were not available were former colonies, it is reasonable to assume that more than $60 \%$ of the world population had a per capita income of less than $\$ 100$ in 1950 (Kuznets, 1968). 
As in 1984, and using the modern division of the world economy (WB- World Development Report 1986), the average per capita income (U.S. dollars, 1984 current prices) range varied from $\$ 260$ in low-income economies, $\$ 1250$ for middle-income economies and around \$2,000 for the former East European (excluding Yugoslavia) non-market economies. Again, on top of the per capita income were the high-income economies of the OECD with an average income per capita of $\$ 11,430$. Portugal, Greece and Turkey, which belong to OECD are included in the upper- middle-income economies. As regards the long-run evolution of the national output, data are only available for the most developed countries. Tables I and II present, respectively ,the evolution of GDP and GDP per capita (in international dollars) of four Western European countries - France, Germany, The Netherlands and U. K., Japan and U.S., in the long-term period 1870-1984. Data are taken from Maddison (1987). It can be seen that the rate of growth throughout the period of analysis was increasing. Particularly striking is the growth process in 1950-1973. During this period, GDP per capita in U.S. had an increase of more than $50 \%$ and in U.K. almost 100\%. Japan increased its per capita GDP by more than fourfold and the remaining countries more than doubled their 1950 level of GDP per head. The process of convergence by the five countries to the leader country (U.S.) was also accelerating. However, Table I also shows that the rate of growth in all countries started to decelerate since 1973. Average GDP growth for the four European countries and Japan fell from 5.6\% per year in $1950-1973$ to $2.1 \%$ per year thereafter, and for the U.S. from $3.7 \%$ to $2.3 \%$.

For the less developed countries, there is no consistent set of data available on the national output prior to 1950. Reynolds (1985) found that 23 out of 41 countries analysed reached the turning point at various points in time between 1850 and 1950, most of them between roughly 1890 and 1914, which corresponded to a period of worldwide economic boom. These successful countries experienced, during this period, a sustained rise in their per capita income, and in some of them (e.g. Argentina before 1914), the development pattern was similar to that of the HIEs during the same period. It should be noted that data used by Reynolds (1985) concern 
agricultural production, exports and population. Another relevant characteristic of the development process pertaining to the LIEs is that some of these countries (e.g. Nigeria, Zambia and Zimbabwe) reached the turning point in the colonial status.

Table 1 GDP Levels at 1984 International Dollars in Selected Industrial Countries; 1870-1984

\begin{tabular}{lcccccc}
\hline & France & Germany & Japan & Netherland & U.K. & U.S. \\
\cline { 2 - 6 } Years & & \multicolumn{7}{c}{ ( I\$ billion ) } \\
\hline 1870 & 59.27 & 33.98 & 19.28 & 8.26 & 77.95 & 78.61 \\
1913 & 119.99 & 111.75 & 54.76 & 20.33 & 174.78 & 454.53 \\
1950 & 173.49 & 179.22 & 124.34 & 49.40 & 281.04 & $1,257.86$ \\
1960 & 271.03 & 387.21 & 295.178 & 76.99 & 372.80 & $1,735.86$ \\
1973 & 547.98 & 675.49 & 976.50 & 142.20 & 556.60 & $2,911.78$ \\
1984 & 694.70 & 811.6 & $1,468.40$ & 168.90 & 625.20 & 3,7465 \\
\hline Source: Maddison (1987) & & & & &
\end{tabular}

Table II GDP per capita at 1984 International Dollars; 1870-1984

\begin{tabular}{lcccccc}
\hline & France & Germany & Japan & Netherland & U.K. & U.S. \\
\cline { 2 - 6 } Years & & \multicolumn{2}{c}{$(\mathbf{I \$})$} \\
\hline 1870 & 1,542 & 1,336 & 560 & 2,290 & 2,671 & 1,962 \\
1913 & 2,878 & 2,737 & 1,060 & 3,298 & 4,101 & 4,657 \\
1950 & 4,147 & 3,600 & 1,486 & 4,884 & 5,000 & 8,261 \\
1960 & 5,933 & 6,985 & 3,136 & 6,703 & 7,093 & 9,608 \\
1973 & 10,514 & 10,899 & 8,987 & 10,581 & 9,902 & 13,741 \\
1984 & 12,643 & 13,235 & 12,235 & 11,710 & 11,068 & 15,829 \\
\hline
\end{tabular}

Source: Maddison (1987)

From the period 1950 (when the United Nations and the World Bank started to publish national accounts statistics of their member sates) onwards, there are a reasonable amount of data on the national output and its components pertaining to the LIEs. In the post World War II period, the rate of growth of GNP per capita in LIEs 
has roughly been the same as in HIEs. However, significant differences in the growth process within the LIEs can be observed. In the period 1965-1990, the average annual growth rate of the GNP per capita was $0.2 \%$ in Sub-Saharan Africa compared to $5.3 \%$ in East Asia \& Pacific. In the same period, the average annual growth rate was $2.5 \%$ and $2.4 \%$ for, respectively, low- and middle income economies and OECD members (World Development Report- WB, 1992).

\section{3-2 Trends in capital formation}

As stated before, capital formation as one component of the national product is measured by net or gross additions to the stock of construction and of production's equipment and net additions to household inventories. Again, the long-term data concern the present-day more developed countries.

Table III- Total Gross Fixed Capital Stock (Asset Weights) at Midyear;

1913-1984

\begin{tabular}{lcccccc}
\hline & France & Germany & Japan & Netherland & U.K. & U.S. \\
\cline { 2 - 7 } Years & \multicolumn{5}{c}{$\mathbf{1 9 5 0 = \mathbf { 1 0 0 }}$} \\
\hline 1913 & $\boldsymbol{*}$ & $\boldsymbol{*}$ & 56.66 & 45.99 & 65.17 & 51.34 \\
1950 & 100.00 & 100.00 & 100.00 & 100.00 & 100.00 & 100.00 \\
1960 & 126.62 & 163.09 & 156.06 & 138.46 & 128.51 & 137.18 \\
1973 & 226.56 & 331.78 & 584.77 & 238.85 & 210.13 & 214.74 \\
1984 & 348.67 & 478.89 & $1,225.73$ & 344.53 & 276.06 & 290.66 \\
\hline
\end{tabular}

Note: .. - not available; Source: Maddison (1987)

Table III presents the evolution of the gross fixed capital formation in six advanced industrial countries in the period 1913-1984. It is observed that, in line with the growth in GDP and GDP per capita (see Tables I and II.), gross fixed capita formation increased in all countries during the period of analysis. It is also shown that 
the country which experienced the fastest rate of economic growth -either measured in GDP or GDP per capita- during the period of analysis (Japan) was the same in which the growth rate in capital formation was faster. However, as suggested in Table III, the rate of growth in the latter indicator in all countries started to decelerate since 1973, following the pattern of the GDP.

The association between capital formation and the evolution of GDP is better understood looking at the Table IV. As pointed out by Maddison (1987: p. 656), the close correlation between capital and output movements over the long-run is the reason simple regressions find physical capital such a powerful explanation of growth.

Table IV Capital Productivity Growth; 1913-1984

\begin{tabular}{lcccc}
\hline & $\mathbf{1 9 1 3 - 1 9 5 0}$ & $\mathbf{1 9 5 0 - 1 9 7 3}$ & $\mathbf{1 9 7 3 - 1 9 8 4}$ & $\mathbf{1 9 1 3 - 1 9 8 4}$ \\
\cline { 2 - 4 } & \multicolumn{4}{c}{ (annual average compound growth rates) } \\
\hline France & 0.12 & 1.50 & -1.82 & 0.23 \\
Germany & 0.56 & 0.57 & -1.71 & 0.20 \\
Japan & 0.69 & 1.39 & -3.41 & 0.28 \\
Netherlands & 0.31 & 0.85 & -1.83 & 0.15 \\
U.K. & 0.13 & $-0,26$ & -1.45 & -0.24 \\
U.S & 0.96 & 0.34 & -0.47 & 0.55 \\
Average & 0.46 & 0.73 & -1.78 & 0.20 \\
\hline
\end{tabular}

Source: Maddison (1987)

As indicated in Table IV, the average of capital productivity (the difference between the compound rate of increase in output and the rate of increase in capital input) of the six countries was $0.20 \%$ per year in the period 1913-1984. Further, capital productivity was positive in the period referred to for all countries, except for U.K. 
However, contrary to labour productivity which seldom declines on a short-run basis, and in the long-run is always positive, capital productivity is moderately positive and can be significantly negative in depressed economic conditions (ibid., p. 657). In the period 1973-1984, capital productivity was negative in all six countries and their average was $-1.78 \%$ per year. This suggests that capital formation is not the only determinant of growth. It is also shown that the U.S. had among its counterparts the highest capital productivity in the long period 1913-1984 and has been the leader country since 1913. It is not surprising that data based on the growth experience of the U.S. was the basic material used in Solow's (1956) neoclassical model of economic growth.

\section{4- The relationship between investment in construction and economic}

\section{growth}

As referred earlier, the indicator used as a proxy for construction investment is construction value added. CVA is calculated the same way as in any other sector, but includes only the activities of the construction activity proper. For example, it excludes the building materials industry which is accounted in the manufacturing sector. The main indicator of economic activity used in this study is GNP per capita. It adjusts the growth in the economy with the growth in population. It is a better indicator of a country's welfare particularly in developing nations, where the growth rate of population has been since the Second World War roughly twice as high as in developed economies.

Using data adapted from the UN Yearbook of National Accounts Statistics (United Nations, 2008 internet edition), Figs I to VII provide data on Gross Domestic Product (GDP) , Gross Fixed Capital Formation (GFCF) and on Construction Value Added (CVA) at constant1990 US\$. 
Cross-matching sources, data is available for 114 countries and these countries can be split into 10 subgroups according to regional location and level of GNP per capita in 1990. Figures II to VIII-9 illustrate the 10 subgroups.

The further subdivision according to the level of GNP per capita in 1990 is used as a proxy for the level of economic development for these countries. This categorisation is not an attempt to apply labels of least-developed through to most developed to the ten groups but represents an arbitrary proxy for a simple classification into three additional subgroups based simply on GDP per capita (Ruddock and Lopes, 2006). The regional groups are as follows:

- Sub-Saharan Africa (S.S.A)

- East Asia and Pacific (E. Asia \& Pacif.)

- South Asia (S. Asia)

- Eastern Europe (E. Eur.)

- OECD-Europe (OECD- Eur.)

- Middle East and North Africa (M. East \& N. Afr.)

- Northern America - USA and Canada (USA \& Can.)

- Rest of Americas (Rest of Am.)

East Asia and the Pacific is further split into three subgroups according to level of per capita GNP in 1990: E. Asia \& Pacif.- LIEs; E. Asia \& Pacif.- MIEs; and E. Asia \& Pacif.- HIE.

Strictly speaking SSA comprises all countries south of the Saharan desert except for a few countries that belonged to middle income range in 1990. E. Asia \& Pacif.- LIEs comprise countries of the low income range including China, Indonesia and Canbodia. Asia \& Pacif.- MIEs comprises middle income countries of East Asia such as Korea Republic, Philippines and Thailand and Malaysia. E. Asia \& Pacif.- HIE comprises Australia, New Zealand and Japan. South Asia is composed of the low 
income countries of that region including India and Pakistan and Sri Lanka. E. Eur. is composed of the middle income countries of Eastern Europe, apart from the countries that were formed after the breakup of the former Soviet Union. OECD- Eur. comprises 14 high- income European countries that are member of the OECD. M. East \& N. Afr. comprises all middle income countries of that subregion except for Egypt and Afghanistan which were considered LIEs in 1990. Rest of Americas comprises practically all countries of South America and the Caribbean, both in the middle income range.

Fig. I -Volume Indices of GDP, GFCF, CVA at constant 1990 US\$ (1970 =100) (World)

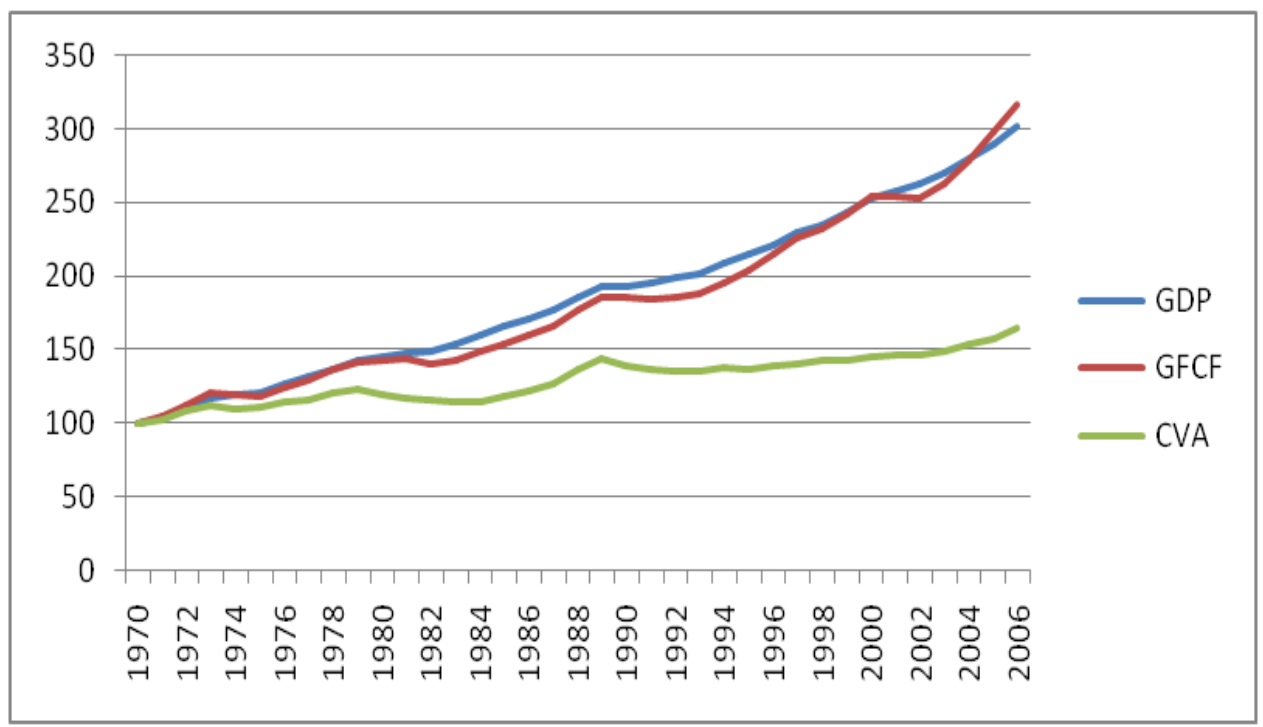


Fig. II -Volume Indices of GDP, GFCF, CVA at constant 1990 US \$ (1970 =100) (SSA)

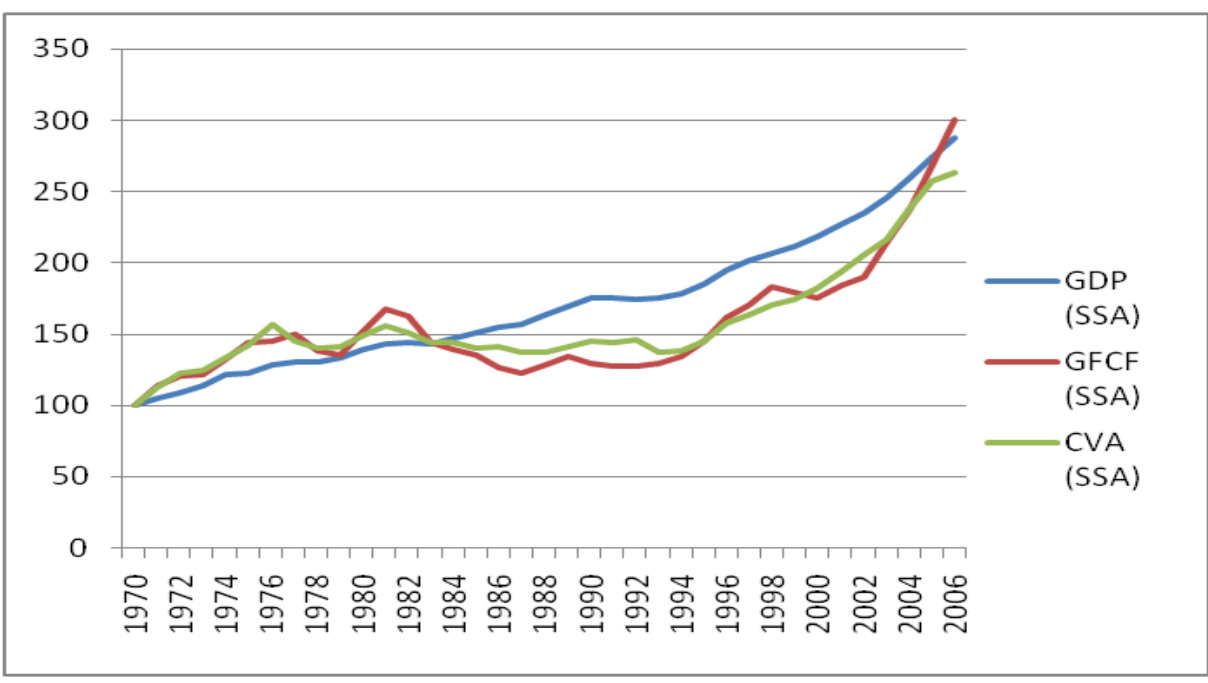


Fig. III.1 -Volume Indices of GDP, GFCF, CVA at constant 1990 US \$ (1970=100) (E. Asia \& Pacif.- LIEs)

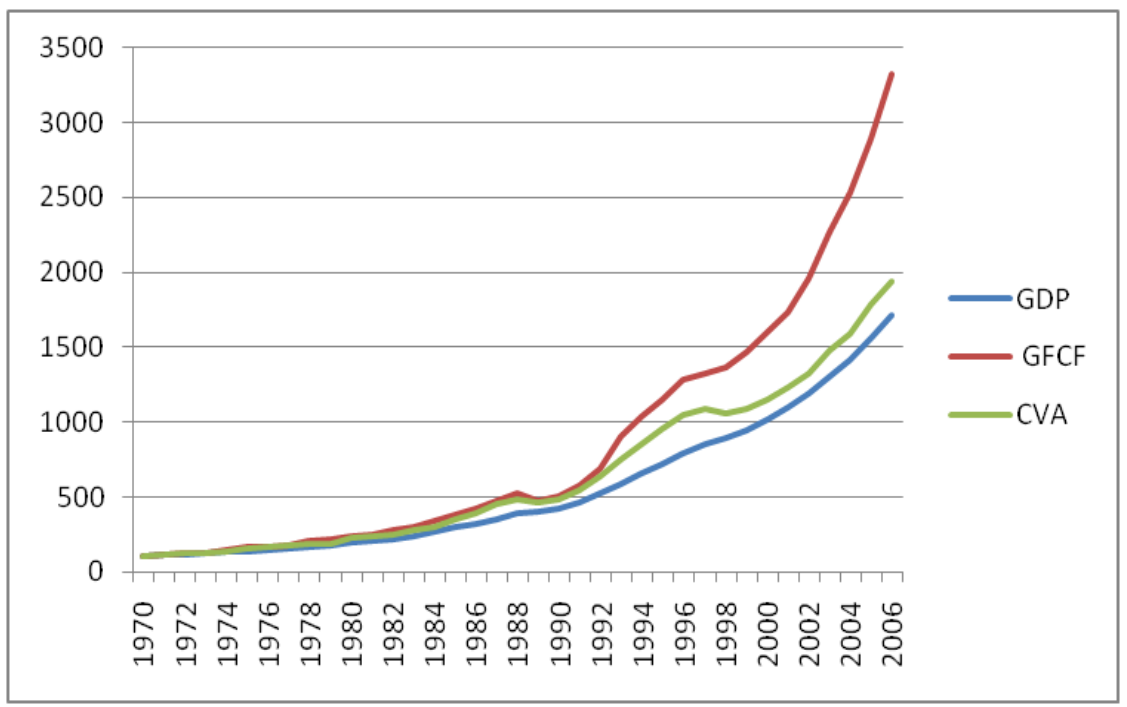


Fig.III.2 Volume Indices of GDP, GFCF, CVA at constant 1990 US\$ (1970=100) (E. Asia \& Pacif.- MIEs)

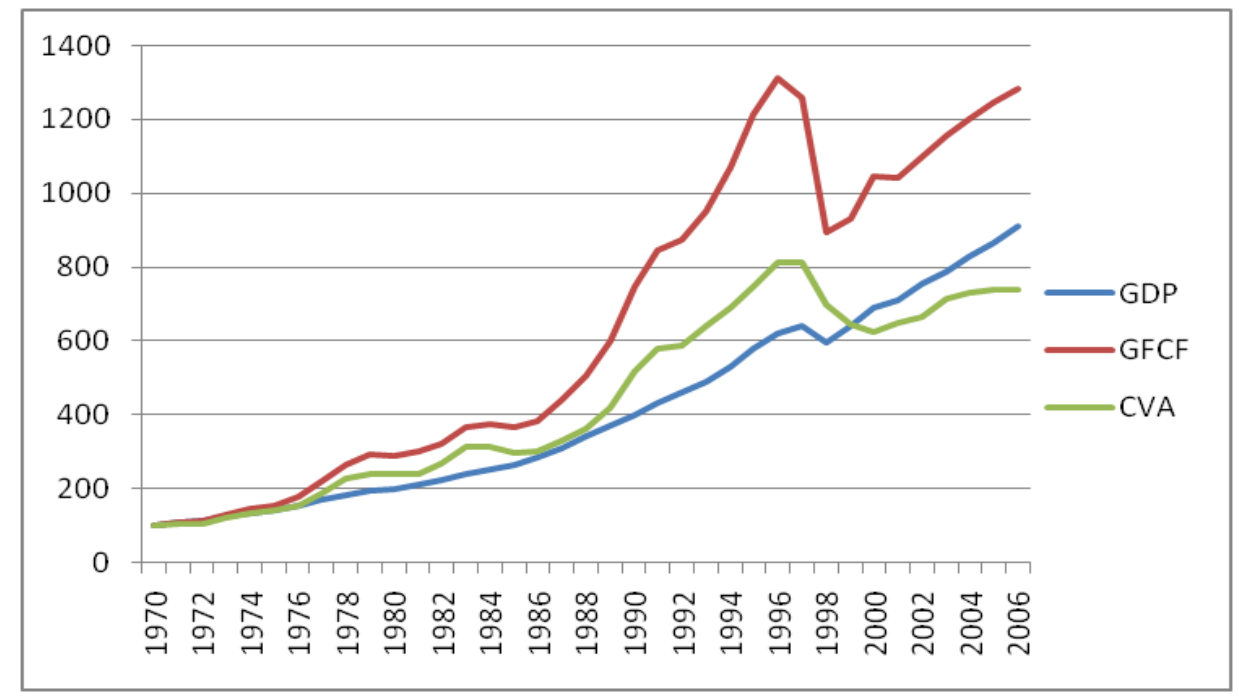


Fig.III.3 Volume Indices of GDP, GFCF, CVA at constant 1990 US\$ (1970 =100) (E. Asia \& Pacif.- HIEs)

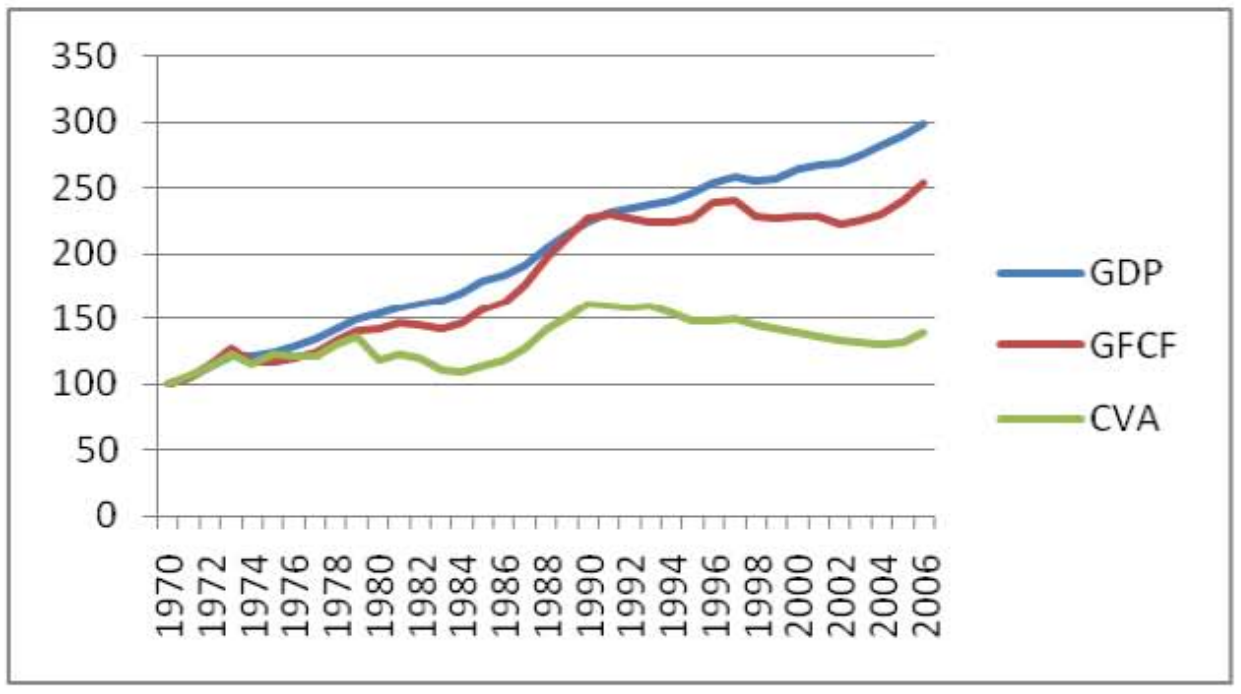


Fig. IV Volume Indices of GDP, GFCF, CVA at constant 1990 US\$ (1970=100) (S. Asia)

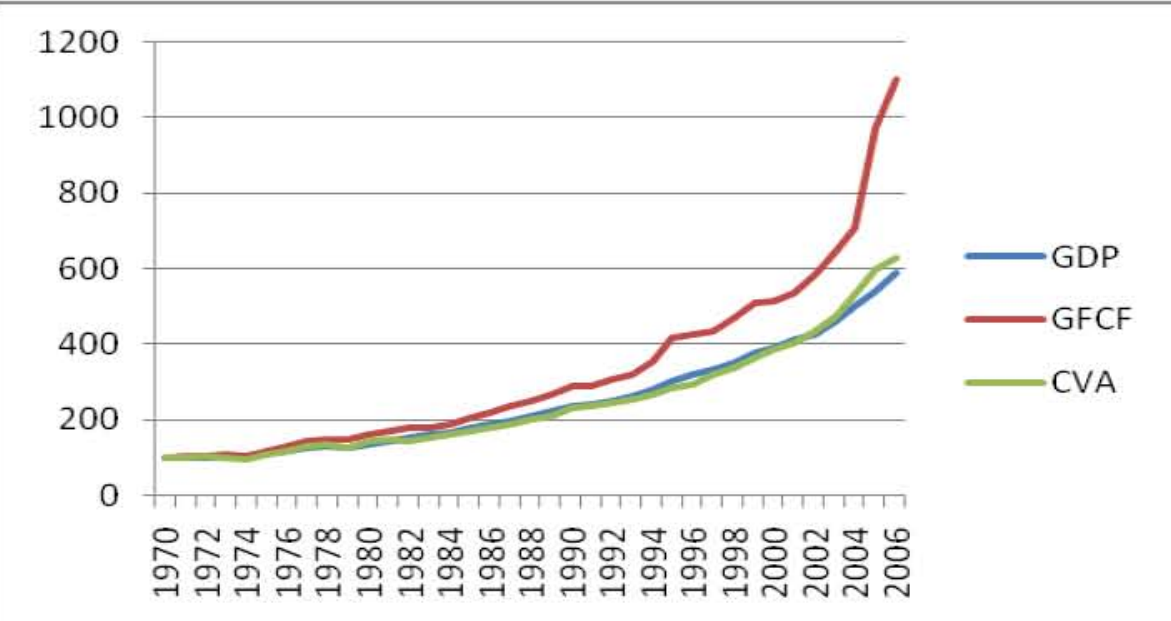


Fig.V- Volume Indices of GDP, GFCF, CVA at constant 1990 US\$ (1970=100) (East Eur.)

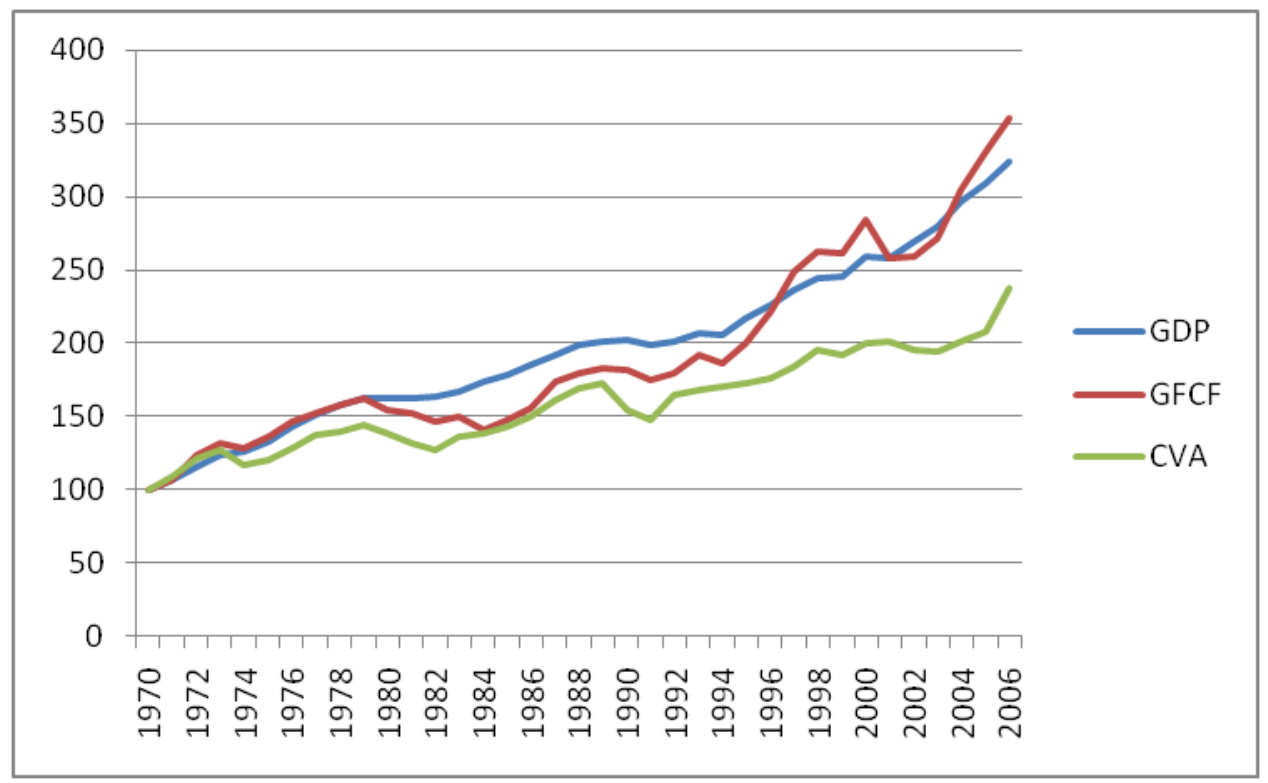


Fig.VI- Volume Indices of GDP, GFCF, CVA at constant 1990 US\$ (1970=100) (OECD- Eur.)

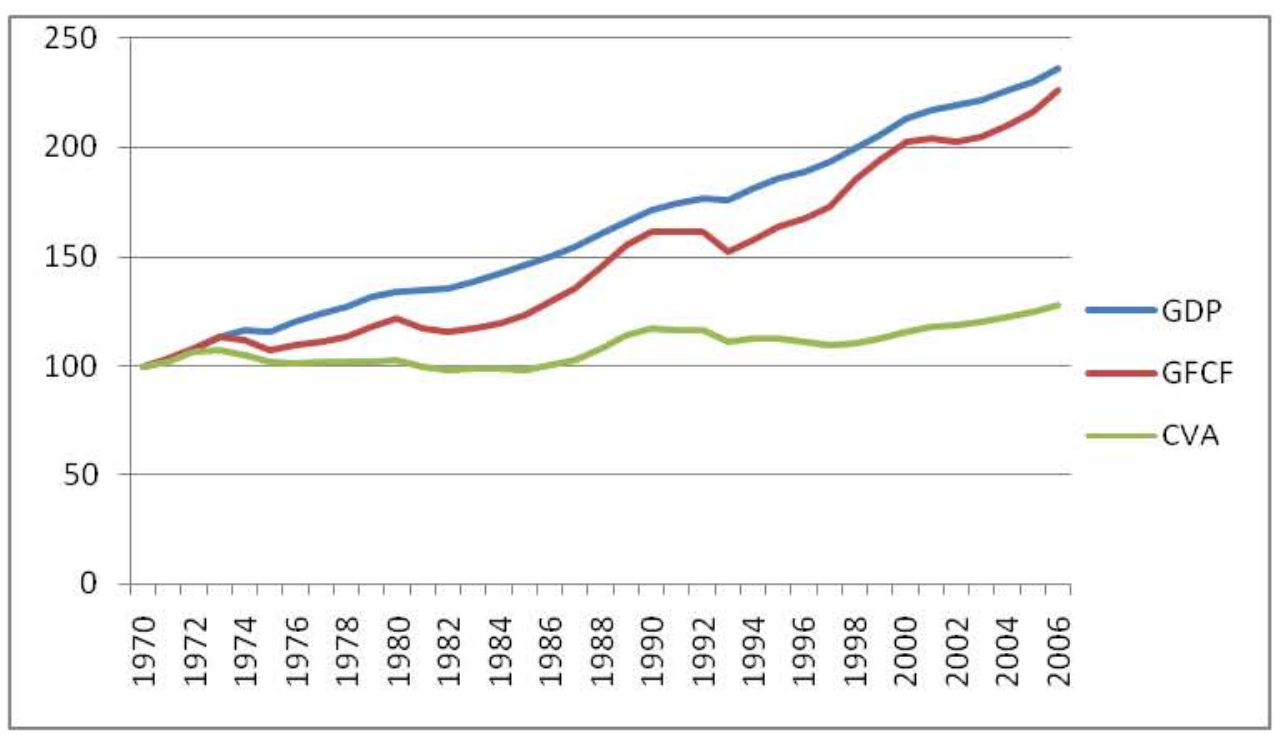


Fig.VII- Volume Indices of GDP, GFCF, CVA at constant 1990 US\$ (1970 =100) (M. East \& N. Afr)

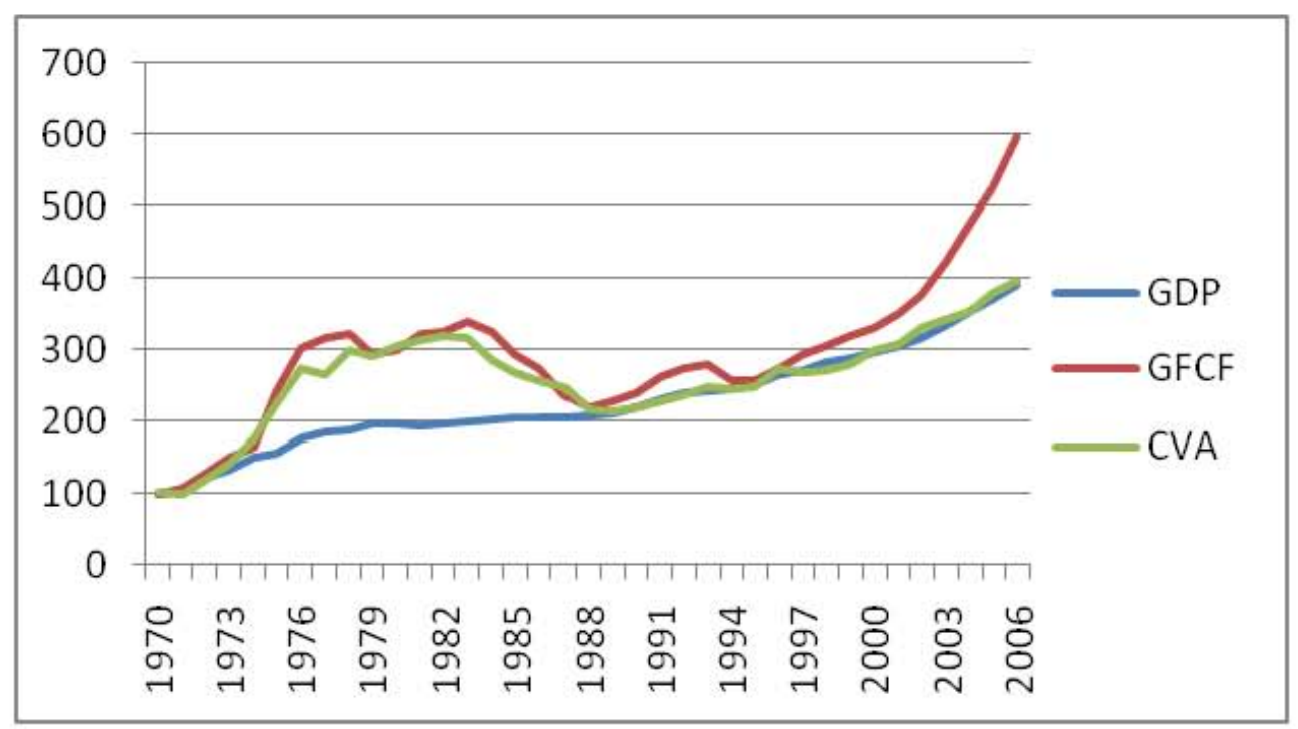


FigVIII -Volume Indices of GDP, GFCF, CVA at constant 1990 US\$ (1970=100) (USA \& Can)

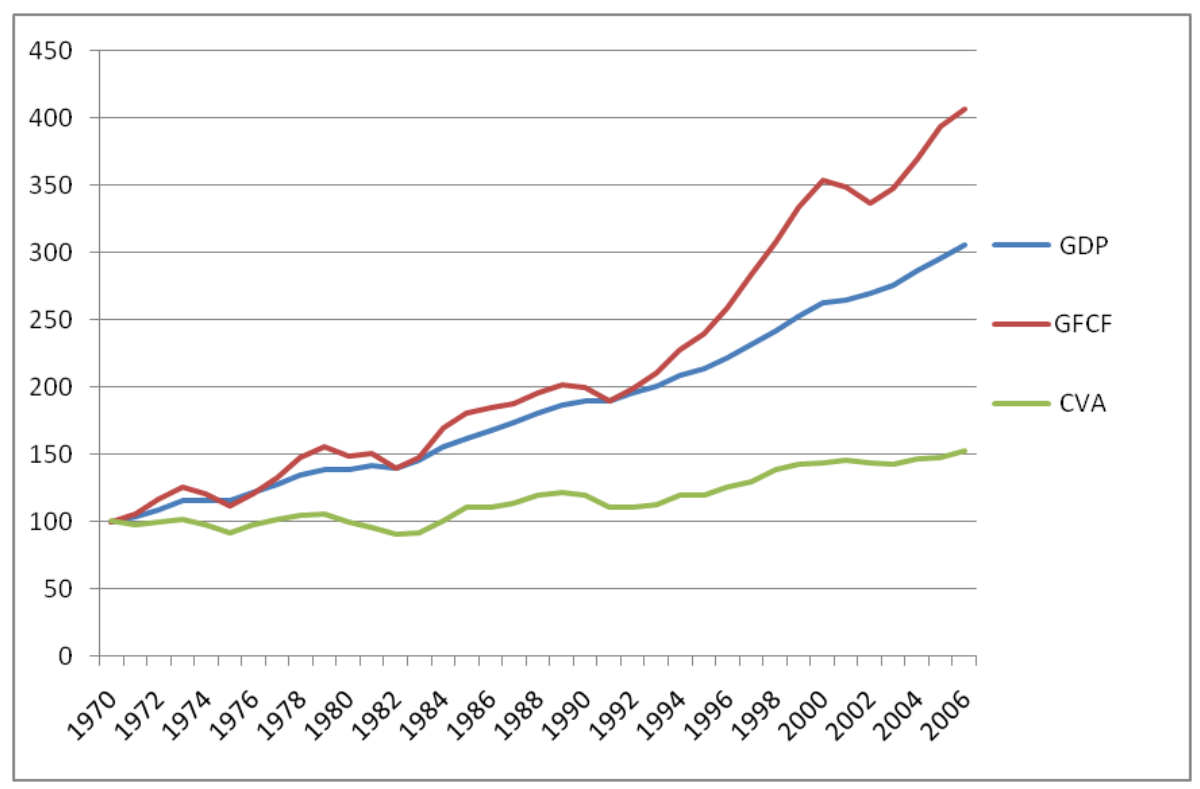


Fig IX -Volume Indices of GDP, GFCF, CVA at constant 1990 US\$ (1970=100) (Rest of Am.)

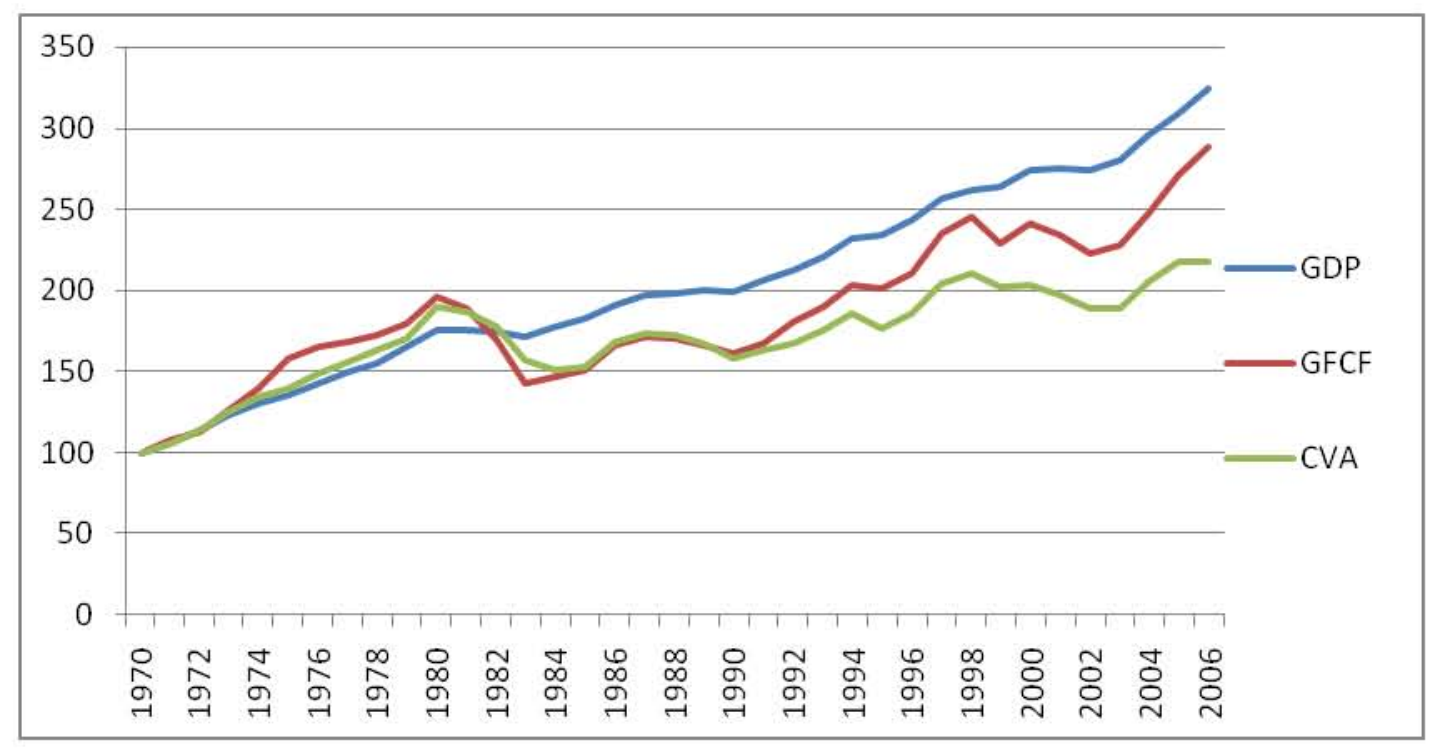




\section{5- Concluding Remarks}

The picture that emerges from the analysis suggests that the share of construction in gross output tends to increase with the level of per capita income in the first stages of economic development. When countries reach a certain level of economic development, the construction output will grow slower than the gross domestic product in the latest stages of their recovery. That is, it decreases relatively but not absolutely. Thus, it is reasonable to assume that when a certain level is achieved (say the share of CVA in GDP around 4 - 5\%, it depends upon the year taken as base) and countries enter into a period of sustained economic growth and development, the construction output tends to grow, in general, with the same rate of growth of that of the GDP.

To demonstrate clearly the relative importance of construction, it is essential that reliable data on the sector are acquired. Ofori (1999), reviewed the problems of data reliability for developing countries and indicated that good quality construction data provide a basis for policy formulation and planning. In a recent report based on an international survey of the usefulness and availability of published statistical information available to the construction macroeconomist (Ruddock, 2000), problems of definition and collection were considered. Out of the various recommendations proposed in the report, the development of single agency responsibility for data collection and the setting-up of regional construction databases are perhaps the most pertinent in this context. 
The construction sector plays an important role in the development strategy of any country that goes beyond its share in national output. Many writers have referred to its effect on employment creation, others to its multiplier effects in the national economy. Another relevant feature should be added: it is the great flexibility of the construction industry activity in adjusting to different framework conditions that makes, particularly, this sector of the economy a major contributor to the process of economic growth and development.

\section{References}

Barro, R. J. (1991), Economic Growth in a Cross Section of Countries, The Quarterly Journal of Economics, 106, May, 407- 43.

Bon, R. (1990), The World Building Market, 1970-1985, Proceedings on the CIB International Symposium on Building Economics and Construction Management, Vol. 1, Sydney, pp. 16-47.

Bon, R. (1992), The Future of International Construction: Secular Patterns of Growth and Decline, Habitat International, 16 (3), 119- 28.

De Long, J. B. and Summers L. H. (1991), Equipment Investment and Economic Growth, The Quarterly Journal of Economics, 106, May, 445-502.

Kuznets, Simon (1968), Towards a Theory of Economic Growth, New York, W. W. Norton.

Lewis, W. A. (1955), The Theory of Economic Growth, London, Allen \& Unwin. 
Lopes, J. (1997), Interdependence between the Construction Sector and the National Economy in Developing Countries: A Special Focus on Angola and Mozambique, Unpublished Ph.D. Thesis, University of Salford, UK.

Ofori, G. (1990), The Construction Industry: Aspects of its Economics and Management, Singapore University Press.

Ofori, G. (2001), Indicators for Measuring Construction Industry Development in Developing Countries, Building Research and Information, 29 (1), 40-50.

Reynolds, L G (1985), Economic Growth in the Third World: 1850 - 1980, New Haven, Yale University Press.

Romer, P. M. (1990), Endogenous Technological Change, Journal of Political Economy, 98 (5), S71- S102.

Ruddock, L. (2000), An International Survey of Macroeconomic and Market Information on the Construction Sector: Issues of Availability and Reliability, RICS Research Papers, Vol. 3, No 11, RICS Research Foundation, London.

Turin, D. A. (1973), The Construction Industry: Its Economic Significance and its Role in Development, UCERG, London.

United Nations (2008-internet edition), Yearbook of National Accounts Statistics, Statistical Office, DESA, New York Publishing Division.

Wells, J. (1987), The Construction Industry in Developing Countries: Alternative Strategies for Development, Croom Helm Ltd, London.

World Bank (1984), The Construction Industry: Issues and Strategies in Developing Countries, IBRD, The World Bank, Washington D.C. 
World Bank, (1986, 1992, 1998, 2008), World Development Report, IBRD, Oxford University Press. 